with establishing or maintaining advocacy schemes which is provided by more recent do-it-yourself guides.

As history, this is closer to a contemporary document than a history textbook. The reader has to do his or her own selection, among a wealth of detail, about who did what and when and why in the early self-advocacy days in North America.

There is confusion in much discussion of self-advocacy between what is strictly self-advocacy, namely people being enabled to speak up in their own interests about their own past, present and future, and the much higher profile 'self-advocacy', which is really group advocacy by members of the group. This early study shows how the one thing blends into the other sometimes the public role helps an individual manage her own destiny more effectively. Sometimes getting a better grip on personal affairs helps someone move on to public affairs. Usually, the two things are mutually supportive.

While the 'criticism' that the People First Movement is based on more able people with learning disabilities is valid, We Can Speak For Ourselves illustrates the fact that few of the publicly prominent self-advocates are 'naturals'. All had to work very hard to become competent spokespersons. This means that there are messages for all those who work with and for people with learning disabilities. That message is about being conscious of the at-times shameful history of society's approach to people with learning disabilities; being conscious of the personal histories of those we are working with; and being open to the possibility that, verbally or not, they understand themselves better than we understand them. It is also about the certainty that unless we pool insights, we shall fail them, as we have so often failed them in the past.

BRIAN MCGINNIS Special Adviser, Mencap.

\section{Choices and conflict: explorations in health care ethics}

Edited by Emily Friedman, Chicago, USA, American Hospital Publishing Inc, 1992, 224 pages, $\$ 42$

Reviewers would do well to remember that generosity is a virtue for them as well as for the rest of humanity. The phenomenon of the clever, negative and archly self-aware review is disagreeably familiar. I hope I will not be thought to be encouraging this style of criticism if I say that I found reading this book a discouraging experience.

The book is an American Hospital Association publication which consists of twenty-eight essays, some new, most reprinted from journals, on a wide variety of topics in health care ethics. The editor has attempted to impose some shape on the collection by grouping the contents around six themes, but this thematic unity is more often than not spurious. Thus some of the essays under the heading of rationing seem to have little to do with that topic.

The authors include ethicists, physicians, lawyers and sociologists. The emphasis of most essays is ethical, though some are more factual and legal in orientation. The quality of the ethical thinking displayed here is, I have to say, somewhat lightweight. This lack of ballast springs in part from the absence of theoretical underpinnings for these moral reflections. When theory does put in an infrequent appearance, as with relativism and the debate between liberals and communitarians, it does so in a form so aetiolated as to be unhelpful. But this theoretical vacuum is not solely responsible for the sense of ethical flimsiness left by the book. There is a more general lack of intellectual penetration and imaginativeness that accounts for this feeling. There are exceptions. Essays by the Director of the Hastings Center and the executive editor of the New England fournal of Medicine are, as one would hope, a little more substantial. And it is a pleasure at last to discern some intellectual and philosophical sinews in a short essay on rationing by the philosopher Norman Daniels. But otherwise, reading this book is the literary equivalent of eating an indifferent blancmange which evaporates on the tongue, leaving little or no taste.

Books of this kind provoke more general reflections. In a scientific culture like ours there is a standing risk of science attracting more talent than ethics. The problems of the former seem so eminently more resolvable than the intractable problems of the latter. Such a tendency of thought was perhaps crystallized in the philosophy of logical positivism and has been more generally sustained by the prevalence in philosophy and outside it of the distinction between facts and values. The recent growth of interest in applied ethics amongst philosophers marks a welcome and significant weakening of this tendency. But one problem in doing applied ethics is how to transcend the sort of superficiality displayed in this book. Some think that the solution is to situate the practical issues in the context of competing moral theories, whose merits are then explored. Whatever the case for this, it does risk substituting intellectual paralysis for thoughtless conviction, not evidently a step forward, particularly for those who shoulder the responsibility of making the moral decisions on the issues in question.

At a moment when the teaching of ethics to health care professionals is beginning at last to be taken seriously, it is crucial that it not be perceived as an intellectually undemanding and lightweight option. If it is, able students will view its inclusion in the syllabus with irritation, and rightly so. The charge against this book, and others like it, is that they foster such a misconception.

WILL CARTWRIGHT Lecturer in Philosophy, University of Essex.

\section{Medicine betrayed: the participation of doctors in human rights abuses}

BMA working party, London/USA, Zed Books Ltd, 1992, 234 pages, $£ 9.95 / \$ 19.95$

This book is the report of a working party set up in 1990 by the British Medical Association under the chairmanship of Sir Douglas Black to look into the abuses of medical skills on prisoners throughout the world and to make recommendations as to how such abuses may be opposed and eradicated. This initiative is a great tribute to the British Medical Association in its role of forming and leading professional opinion, since the report clearly identifies how equivalent organizations in other countries have failed to speak out and condemn such practices, whether through inertia, tacit approval or direct political interference in their activities, and have thereby facilitated the development or continuation of such abuses.

The territory covered is familiar medical involvement in torture, the abuse of psychiatry for political purposes, the involvement of doctors in corporal and capital punishment and 
unethical treatment of a variety of kinds within prison systems. However, the evidence is assembled from an impressive variety of sources, subjected to careful critical analysis and set out in a systematic way which can only impress with its transparent genuineness and remorseless weight. The reader is left with no escape from the conclusion that doctors through overwhelming pressure, cowardice, lack of peer support, lack of self-criticism or awareness and even personal conviction and relish have betrayed the principles of their profession, often in the recent past and often not far from home.

The response of the working party is forthright, unequivocal and convincing. They have no time for compromise or self-justification. What they have found must be stopped and it is the duty of any doctor who comes across such abuses to be actively involved in bringing them to notice and preventing their continuation. The list of recommendations is practical and sympathetic as well as far-reaching. The importance of peer solidarity and support and the need for independent and active professional organizations is stressed. However, such is the power and conviction of this report that I am left wondering how much that is taken for granted, but which lies close to the subject matter can ultimately escape the same censure.

If it is unethical, and I accept that it is, for a psychiatrist to argue in a court of law in a jurisdiction that may invoke the death penalty to the effect that a man or woman is mentally competent to be executed, ie he or she has no mental abnormality which takes him or her outside the scope of the death sentence, is it ever ethical in any trial on any charge for a psychiatrist to testify for the prosecution to the effect that mental abnormality is absent? On what ethical basis has the examination taken place and the confidences been elicited which may ultimately lead to a, relatively, harsher disposal?

If it is unethical, and I accept that it is, for a doctor to be party in any way to the infliction of cruel, inhuman or degrading treatment or punishment, when is it acceptable for a doctor to work within a penal establishment? $\mathrm{He}$ will necessarily at times be asked to treat conditions, such as depression, which are the direct result of the patient being in a penal establishment. Should he any more be involved in restoring the mental equilibrium of such an individual during the remainder of a prison sentence than in treating a mentally ill condemned man so that he is well enough to be executed? Ultimately the question that remains tantalizingly unanswered is when is punishment not cruel, inhuman or degrading? Paradoxically, through condemning so eloquently the identified abuses of medicine, that which is not condemned seems to be giveri a degree of immunity for which an extension of the report's own arguments appears to provide no justification.

It is my personal, somewhat tentative view that in the fullness of time our present treatment of offenders of all kinds will seem as evil and incomprehensible as we now find the antics of the Spanish Inquisition or the severe penal policies of two hundred years ago. This book strengthens such convictions and provides further support to those who have rightly questioned the approach of our own society to the use of imprisonment and the role of a prison medical service employed directly by the Home Office.

CHRISTOPHER HOWARD Academic Department of Psychiatry, Royal Free Hospital, London.

\section{Compelled compassion - government intervention in the treatment of critically ill newborns}

Edited by A L Caplan, R H Blank, and Janna C Merrick, Totowa, New Jersey, USA, Humana Press, 1992, 360 pages, $\$ 49.05$

This book is a compilation of essays by twelve leading authorities in the field of applied medical ethics. It sets out from a variety of viewpoints the facts and the circumstances of the changes in neonatal intensive-care-unit practice in the United States before, during and after the controversial circumstances surrounding the care of several handicapped babies, with the legal and political interventions accompanying them. This broadly covers the ten-year period following the death of Baby Doe. Beginning with the medical and legal uncertainties which surround neonatal intensive care and proceeding to several reviews of the facts in and around those controversial cases, some penetrating questions are set and fully discussed by several authors. These questions include the ontological status of neonates, the disabilities which $\frac{\widehat{Q}}{\mathrm{Q}}$ may follow survival in severelym compromised babies and the ways in which value judgements may be made $\bar{\AA}$ about what might be done and the potential outcomes. Also discussed atç great length is the issue of who should best contribute to decisions about such $\frac{}{0}$ infants: the parents, the doctors in $\overline{\bar{\omega}}$ charge, or others, whether empowered $\overbrace{\overparen{D}}$ by law or not. The general outcome, $\stackrel{\varrho}{ }$ albeit set around with debate, is that the best interests of the baby should be $\vec{\circ}$ the main determinant. The problems:which are exposed are how those best $\vec{\omega}$ interests may be served, and what contribution litigation, resource-funding and family attitudes or presuppositions $\mathbb{D}$ may have towards serving those $\mathrm{O}$ interests. There is a particularly clearset of debates about the expectations of parents and bystanders, especially when shaped by new technology, ando the immense difficulty of decisions about resource allocation when, as is $\vec{Z}$ clearly the case in neonatal intensive care, resource funding has well passed $\widehat{\widehat{T}}$ the ceiling available. Useful byproducts of this discussion include $\overrightarrow{0}$ the immense variations in resourg- $\$$ funding within and between differmit countries, and the remarkable difficuties imposed by non-linear, evon threshold effects in the relationship between the severity of the child's disability and the resource used to prolong으 life. Not least among the valuable $\vec{\overrightarrow{ }}$ elements in this book are the tabled $\frac{0}{3}$ facts relating to these arguments, for example, the numbers of people who received care at times over the last two decades and at a given cost within the United States.

Some major outcomes of the debate $\frac{\sigma}{3}$ include ample evidence that the inter-?. vention of the law did little to change음 the situation or to help; indeed, it seems often to have defeated even its윽 own objectives. Also, public perception of the severity of the problem haso been shown to have been severely inaccurate. Lastly, there are severalo elegant demonstrations that there is $\mathrm{N}$ little point in getting the ethics right for the short term if the long-term $\omega$ sequels of those decisions are not taken into account as well. There is ano extended discussion of the ways in $\bar{\varnothing}$ which the economic problems of allo-? cating health care might be resolved 0 and the consequences of each. Taken $\overline{0}$ altogether, a remarkably clear, infor- $\overrightarrow{\mathbb{D}}$ mative and penetrating discussion of $\mathrm{a} \frac{\widetilde{\Phi}}{\mathrm{D}}$ major problem of medical ethics $\frac{0}{\sigma}$ which has clear implications for many other such problems beyond it; a book that would make useful reading for 